\title{
Preoperative pain treatment in acute abdomen in Osogbo, Nigeria: a randomized double-blind placebo-controlled study
}

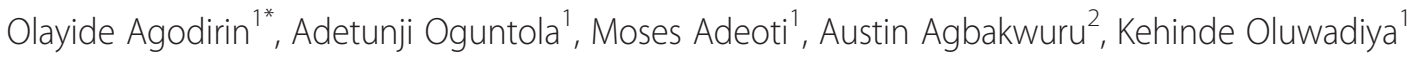 \\ and Babatunde Olofinbiyi $i^{3}$
}

\begin{abstract}
Background: Withholding analgesics in acute abdomen for fear of masking clinical features and impairing diagnosis and decision-making is still being practiced despite recent evidence to the contrary. This study assesses the effect of preoperative analgesia on clinical findings, clinical diagnosis, and decision-making in patients with non-trauma acute abdomen.
\end{abstract}

Method: This is a randomized, double-blind, placebo-controlled study using Tramal, a brand of tramadol, at the ED of LAUTECH Teaching Hospital Osogbo, Nigeria. Ninety-five patients between 18-60 years received Tramal $(n=46)$ or placebo $(n=49)$. The pain score, clinical findings, provisional diagnosis, and treatment plan were noted before and 15-20 min after administration of the analgesic or placebo. The final diagnosis arrived at after adequate investigation or operation was considered the gold standard. The pain scores, diagnosis, treatment plan, and decision between the two groups were compared. Statistical analysis was by SPSS 16. Results were considered statistically significant at $p<0.05$.

Results: Demography and case distribution were similar in both groups. The improvement in pain was greater in the Tramal group $(p=0.001)$. The abdominal palpation findings were also better in the Tramal group $(p=0.02)$. There were more changes in the diagnosis after use of Tramal $(p=0.01)$. There were more changes in the decision in the Tramal group $(p=0.03)$. Most of the changes in diagnosis and decision in the Tramal group were for the better.

Conclusion: The preoperative use of Tramal in acute abdomen improved the experience of pain and did not adversely affect the accuracy of the diagnosis or decision-making.

Keywords: Acute abdomen, Analgesic, Preoperative, Diagnosis, Opioids

\section{Background}

Acute abdomen is the presence of clinical features of intra-abdominal disease that is likely to require surgical intervention for its resolution [1-3]. Because there are numerous causes of acute abdomen, the diagnosis may be a puzzle. Unraveling this puzzle requires obtaining adequate history and examining the patient methodically [3-5]. About $70 \%$ of the times, the history and examination, if well conducted, will lead to the diagnosis $[1,3]$.

\footnotetext{
* Correspondence: cancer1992@yahoo.com

'Department of Surgery, LAUTECH Teaching Hospital, Osogbo, Nigeria

Full list of author information is available at the end of the article
}

Pain is often the dominant complaint in patients with acute abdomen $[1,3,6,7]$. Pain (Latin: poena), true to its Latin meaning "to punishment or torment," is an unpleasant but protective response to actual or potential tissue damage [8]. In patients with acute abdomen uncontrolled pain may produce an uncooperative patient, thus adding to the difficulty of clinical diagnosis. Uncontrolled abdominal pain may also lead to atelectasis and chest infection from involuntary splinting of respiratory muscles. Tachycardia, hypertension, modification of coagulation and the fibrinolytic system, and lengthy admission are all recognized sequelae of uncontrolled pain [8]. 
The issue of the safety of providing analgesia for patients with acute abdomen is marked by longstanding controversy over the possible masking of clinical findings and delaying diagnosis [8-10]. In "Early diagnosis of the acute abdomen," Sir Zachary Cope suggested: "Though it may appear cruel it is really kind to withhold morphine (analgesia) until one is certain or not that surgical interference is necessary" [9]. This reluctance to provide adequate analgesia in acute abdominal pain originated in an era of relative medical underdevelopment when the abdomen was considered a "Pandora's box" and at a time when morphine was given in doses large enough to sedate patients [8-10]. Since then, many studies have suggested that the administration of analgesics does not hinder accurate diagnosis or treatment and may even be helpful $[8,11,12]$. Furthermore, increased knowledge about the use of opiates has evolved. Despite this body of knowledge, preoperative analgesia is still avoided in patients with acute abdominal pain for fear of masking the pathology [8,9,13-18]. In keeping with the prediction in the current edition of Cope's book that old habits may be difficult to kill in the matter of withholding analgesics in patients with acute abdomen [19], in Nigeria the traditional practice of withholding analgesia is still common $[10,20]$.

This study aims at assessing the effect of preoperative analgesia on the clinical findings, diagnosis, and decisionmaking in patients presenting with non-trauma acute abdomen at the emergency department of our hospital. We hypothesize that preoperative analgesia does not affect the clinical features.

\section{Methods}

This was a prospective, randomized, double-blind placebo study using a synthetic opioid analgesic, the Tramal brand of Tramadol (Grunenthal, Germany), as the active agent and water for injection (WFI) as placebo. It was carried out in the emergency department (ED) of our hospital between October 2008 and May 2010.

The institution's ethical approval was obtained before commencement of the study, and all randomized patients gave informed consent. All the randomized patients were first seen by the casualty officer, who invited the primary investigator. The primary investigator reviewed the patient's clinical findings, scored the initial pain (P1) on a numerical rating scale of zero to ten where zero is no pain and ten is the worst pain ever experienced, made a provisional diagnosis (D1), and then proposed the treatment plan (T1).

A third party who was not involved in the patient management presented the patient with an opaque paper bag from which the patient randomly picked an envelope containing the grouping letters 'A' for active agent and ' $\mathrm{P}$ ' for the placebo. The third party administered either $2 \mathrm{ml}(100 \mathrm{mg})$ of tramadol (TRA) or $2 \mathrm{ml}$ of water for injection (WFI) intravenously, depending on the group picked by the patient. The group picked and the agent administered were unknown to both the patient and the primary investigator. Fifteen to 20 minutes after the administration of the study agent, the primary investigator reviewed the patient again. The residual pain score was recorded as $\mathrm{P} 2$, the new provisional diagnosis as D2, and the new treatment plan as T2. The final diagnosis (D3) was determined postoperatively or after adequate investigation if the patient did not undergo an operation. The definitive treatment (T3) given to the patients was based on the demands of their illness. The diagnosis D3 and the treatment T3 were considered the gold standard against which the D1 and D2 and T1 and T2 were compared. Documentation was stopped for all patients upon discharge from inpatient care. Un-blinding was done after randomization had been closed, and collation and analysis were commenced.

The analysis of treatment, either conservative or operative, and the incision types were based on intention to treat (i.e., patients were considered to be members of whichever treatment group they were originally assigned to regardless of whether or not they took the appropriate or prescribed therapy in part or completely).

The change in clinical diagnosis was considered the primary outcome, and this was used to calculate the sample size because the observed clinical features led to the clinical diagnosis, and the treatment decision was a function of the clinical diagnosis.

In calculating the sample size, a retrospective review of the patients presenting at the ED in the preceding 12 months showed that the accuracy of the provisional diagnosis of all the patients $(N=242)$ managed for acute abdomen was $60 \%(145 / 242)$. This information was used to find the sample size $(n)$ for this study using the modified Kirkwood formula for comparison of two groups [21]: $n=(\mathrm{u}+\mathrm{v})^{2}\left\{\mathrm{P}_{1}\left(1-\mathrm{P}_{1}\right)+\mathrm{P}_{2}\left(1-\mathrm{P}_{2}\right)\right\} /\left(\mathrm{P}_{1}-\mathrm{P}_{2}\right)^{2}$.

The desired level of significance, $\mathrm{v}$, for this study was $5 \%(0.05) \mathrm{v}=1.96$ (the two-tailed $\mathrm{z}$ value). The chance of detecting an actual difference, that is, the power of the study $(\mathrm{u})$, was set at $75 \%, 0.67$. How large should the difference be between the proportion in one group and the proportion in the other group $\left(\mathrm{P}_{1}-\mathrm{P}_{2}\right)$ for it to be clinically significant? For this study we took $\mathrm{P}_{1}$ as $0.60[60 \%$, accuracy of clinical (preemptive) diagnosis in the retrospective study] and $\mathrm{P}_{2}$ as 0.85 (that is, to achieve a difference of 0.25).

$$
\begin{gathered}
n=(1.96+0.67)^{2}\{0.60(1-0.60)+0.85(1-0.85)\} \\
/(0.60-0.85)^{2}=40.67 \approx 41
\end{gathered}
$$

Hence, at least 41 patients were required in each group for this study. 
Data analysis was done using SPSS version 16. Statistical analyses were performed using Student's $t$-test, paired $t$-test (signed ranked), Mann-Whitney U-test, and chi-square or Fisher's exact test as appropriate. Exclusion criteria included abdominal symptoms more than 7 days before presentation, hypotensive or obtunded patients, inability to comprehend the pain scoring method, reaction to tramadol or opiates, and prior treatment with analgesics in the course of the illness. Patients below 18 and above 60 years were also excluded to ensure homogeneity of the patient pool and dosing of the active agent. During randomization, no attempt was made to match the groups for age, sex, or clinical diagnosis. Randomization was done only when both the primary investigator and the third party were available; this was to eliminate interobserver differences.

\section{Results}

Ninety-five patients aged between 18 and 60 years received either Tramal injection $(n=46)$ or WFI $(n=49)$. The median age in the two groups was 30.0. Males were $54.3 \%$

\section{Table 1 Distribution of the definitive diagnosis (D3)}

\begin{tabular}{|c|c|c|c|}
\hline & Definitive diagnosis (D3) & Tramadol & Placebo \\
\hline 1 & Acute appendicitis & 14 & 19 \\
\hline 2 & Typhoid ileal perforation & 5 & 1 \\
\hline 3 & Typhoid enteritis & 4 & 6 \\
\hline 4 & Adhesive intestinal obstruction & 4 & 3 \\
\hline 5 & Perforated pud & 3 & 2 \\
\hline 6 & Acute exacerbation of pud & 3 & 0 \\
\hline 7 & Perforated appendix & 2 & 2 \\
\hline 8 & Acute cholecystitis & 2 & 1 \\
\hline 9 & Sigmoid volvulus & 2 & 1 \\
\hline 10 & Appendiceal abscess & 2 & 0 \\
\hline 11 & Appendiceal mass & 0 & 1 \\
\hline 12 & Anastomotic colonic stricture & 0 & 1 \\
\hline 13 & Acute pancreatitis & 0 & 1 \\
\hline 14 & Perforated colonic tumor & 0 & 1 \\
\hline 15 & Amebic colitis & 1 & 1 \\
\hline 16 & Infected colonic tumor & 0 & 1 \\
\hline 17 & Symptomatic ovarian cyst & 1 & 1 \\
\hline 18 & Peritonism (reduced strangulated hernia) & 1 & 1 \\
\hline 19 & Pelvic inflammatory disease & 1 & 1 \\
\hline 20 & Residual abscess & 0 & 1 \\
\hline 21 & Perforated colon (post-colonoscopy) & 0 & 1 \\
\hline 22 & Infected renal cyst & 0 & 1 \\
\hline 23 & Abdominal tuberculosis & 0 & 1 \\
\hline \multirow[t]{2}{*}{24} & Gastroenteritis & 0 & 1 \\
\hline & Total & 46 & 49 \\
\hline
\end{tabular}

and $47 \%$ in the tramadol and placebo groups, respectively. The sex proportions in the two groups were not statistically different $(p=0.47)$.

The distribution of the definitive diagnosis (D3) is shown in Table 1: $75.7 \%$ had general surgical conditions, 19.0\% medical conditions, $4.2 \%$ gynecological conditions, and $1.1 \%$ urological conditions. The most frequent diagnosis was acute appendicitis (34.7\%). There was no statistically significant difference in the proportion of non-general surgical causes of acute abdomen in the two groups $(9 / 46$ in the tramadol group vs. $12 / 49$ in the placebo group, $p=0.56$ ). Also the proportion of patients with acute appendicitis in the two groups was not statistically different $(p=0.39)$; see Table 1 .

The reduction in pain after administration of the study agents is shown in Table 2; the comparison of the change in pain is shown in Figure 1. After administration of Tramal, there was better localization of the abdominal tenderness in 13 patients, and 11 patients were less evasive toward abdominal palpation. In the placebo group, eight had better localization, while six allowed better palpation $(p=0.02)$. After administration of the study agents, there were more cases of discordance between the D1 and D2 in the tramadol group than in the placebo group (10/46 vs. $2 / 49, p=0.01)$ (see Table 3$)$. Injection of Tramal made eight of the diagnoses better but induced diagnostic confusion in two patients. WFI made the diagnoses better in two patients; there was no diagnostic confusion in the remaining 47 patients who had no change in diagnosis (see Table 3).

Operative treatment was proposed for 28 and 32 patients after the D1 in the tramadol and placebo groups, respectively. After the administration of tramadol, changes

Table 2 Change in pain

\begin{tabular}{|c|c|c|c|c|}
\hline \multirow{2}{*}{$\begin{array}{l}\text { Agent } \\
\text { Frequency of pain score }\end{array}$} & \multicolumn{2}{|c|}{ Tramadol } & \multicolumn{2}{|c|}{ Placebo } \\
\hline & $\overline{\mathrm{P} 1}$ & P2 & $\overline{\mathrm{P} 1}$ & P2 \\
\hline 0 & - & 3 & - & - \\
\hline 1 & - & 3 & 1 & 2 \\
\hline 2 & - & 6 & 5 & 8 \\
\hline 3 & - & 2 & 1 & 7 \\
\hline 4 & 5 & 9 & 9 & 3 \\
\hline 5 & 11 & 6 & 9 & 16 \\
\hline 6 & 1 & 6 & 3 & 3 \\
\hline 7 & 4 & 6 & 8 & 6 \\
\hline 8 & 9 & 4 & 5 & 1 \\
\hline 9 & 6 & 1 & 2 & 2 \\
\hline 10 & 10 & - & 6 & 1 \\
\hline Total $(n)$ & 46 & 46 & 49 & 49 \\
\hline \multirow{2}{*}{$\begin{array}{l}\text { Wilcoxon signed-rank test } \\
\text { (for equality of median) }\end{array}$} & \multicolumn{2}{|c|}{$\mathrm{Pl}>\mathrm{P} 2$} & \multicolumn{2}{|c|}{$\mathrm{Pl}>\mathrm{P} 2$} \\
\hline & \multicolumn{2}{|c|}{$P<0.0001$} & \multicolumn{2}{|c|}{$P<0.0001$} \\
\hline
\end{tabular}




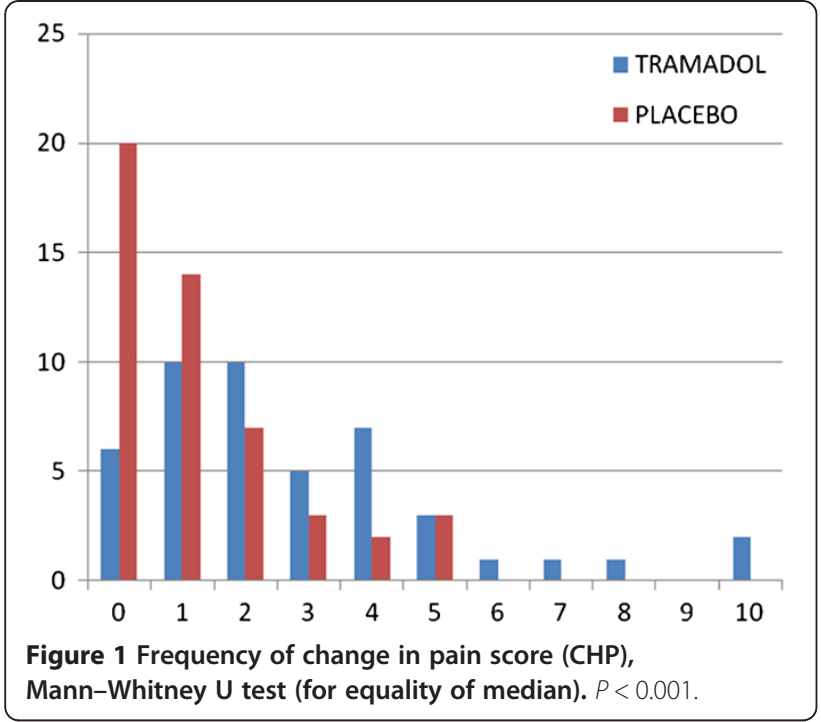

in decision were more frequent (9/28) compared to the placebo group $(2 / 32)(p=0.03)$.

The rate of complications or appearance of new symptoms was not different: five in the tramadol group and two in the placebo group $(p=0.19)$. All the reported symptoms were non-severe. No patient had respiratory difficulty or hypotension. In the tramadol group 40 patients were discharged, 3 died, and 3 discharged themselves against medical advice (DAMA). Forty-four patients in the placebo group were discharged, and 5 patients died. The median duration of admission was 6 days in both groups.

\section{Discussion}

Several studies indicated inadequate perioperative analgesia and inadequate analgesia for acute and chronic pain worldwide $[20,22,23]$. In Nigeria, nearly half of our patients, especially non-trauma surgical patients, have no analgesic prescribed prior to definitive surgical intervention [20]. This may be because, coupled with Cope's pronouncement, the teaching is to treat the cause rather than the symptom, but it is sometimes necessary to administer analgesics preoperatively to mitigate the many untoward effects of uncontrolled pain.

In this study, acute appendicitis was the most common cause of acute abdomen, similar to other documentations, and postoperative adhesion the most common cause of intestinal obstruction. The latter is attributed to the increased rate of laparotomy [22,24-27].

The improvement in pain score after the injection of tramadol being greater than after the use of the placebo is expected. Also, the improvement in abdominal pain

Table 3 Table of discordance in diagnosis (change in diagnosis)

\begin{tabular}{|c|c|c|c|c|c|}
\hline Agent & D1 & D2 & D3 & Comment & Implication \\
\hline$\overline{W F I}$ & APan & APan & ATB & No impact on diagnosis & \\
\hline WFI & Apmass & Apmass & Ap & No impact on diagnosis & Inappropriate incision \\
\hline WFI & Apmass & Apmass & Ap & No impact on diagnosis & Inappropriate incision \\
\hline WFI & PAp & Ap & Ap & Better diagnosis & Better/appropriate incision \\
\hline WFI & PAp & Ap & Right IRC & Localized clinical signs & Better incision \\
\hline WFI & PAp & PAp & $A p$ & No impact on diagnosis & Inappropriate incision \\
\hline WFI & PAp & PAp & Ap & No impact on diagnosis & Inappropriate incision \\
\hline WFI & $\mathrm{TP}$ & $\mathrm{TP}$ & $\mathrm{TE}$ & No impact diagnosis & Unnecessary operation \\
\hline WFI & $\mathrm{TP}$ & $\mathrm{TP}$ & $\mathrm{TE}$ & No impact on diagnosis & Unnecessary operation \\
\hline TRA & Ap & SOC & SOC & Better diagnosis & Averted unnecessary operation \\
\hline TRA & Apmass & $A p$ & Ap & Better diagnosis & Appropriate incision \\
\hline TRA & Apmass & $A p$ & $A p$ & Better diagnosis & Appropriate incision \\
\hline TRA & ApAbs & Apmass & ApAbs & Diagnostic confusion & Wrong treatment/incision \\
\hline TRA & PAp & Ap & Ap & Better diagnosis & Better incision \\
\hline TRA & PAp & Ap & Ap & Better diagnosis & Better incision \\
\hline TRA & PAp & Ap & PAp & Diagnostic confusion & Wrong incision \\
\hline TRA & $\mathrm{H}$ abs & $A C$ & $A C$ & Better diagnosis & Appropriate treatment \\
\hline TRA & AIP & No mass & No mass & Better clinical exam & Better diagnosis \\
\hline TRA & pPUD & aPUD & aPUD & Better diagnosis & Averted unnecessary operation \\
\hline TRA & $\mathrm{TP}$ & $\mathrm{TP}$ & PAp & No impact on diagnosis & \\
\hline
\end{tabular}

Note: $A C$, acute cholecystitis; $A I P$, adhesive inflammatory phlegmon; $A p$, acute appendicitis; $A p A b s$, appendiceal abscess; Apan, acute pancreatitis; ApMass, appendiceal abscess; ATB, abdominal tuberculosis; Habs, hepatic abscess; IRC, infected renal cyst; Pap, perforated appendix; $p P U D$, perforated PUD; aPUD, acute exacerbation of PUD; SOC, symptomatic ovarian cyst; TE, typhoid enteritis; TP, typhoid ileal perforation. 
demonstrated after the injection of tramadol is similar to the documentation by Mahade et al. on the use of intramuscular tramadol in acute abdominal pain [17]. Some studies involving other opioids have found conflicting results when compared to placebo $[8,25]$.

In this study, in the tramadol group, there was better improvement in the abdominal palpation findings with respect to localization of area of inflammation and disposition of the patients to palpation; the patients were more comfortable and less evasive of abdominal palpation after injection of tramadol. This is an objective confirmation of the subjective pain symptom improvement. The comfort brought to the patient and the acceptance of abdominal examination are very desirable events in the management of patients with acute abdomen because they make gathering information easier. The improvements in pain score and examination findings support the hypothesis that analgesics improve the clinical features against the view that the clinical signs are not affected by pain relief [11]. In this study, however, the placebo effect was also demonstrated. The placebo effect is a psychological effect whereby the believe that an agent has been given to relieve pain and the anticipation of the relief cause release of endogenous opiates, giving the anticipated, desired relieving effect $[13,26]$.

The change in clinical finding in the tramadol group translated into a significant change in the clinical diagnosis in $17 \%$ of the patients in this group. The change in diagnosis was for the better more than $75 \%$ of the times, but it led to diagnostic confusion in the remainder. Even though this suggests that the use of analgesic has the potential to make the clinical diagnosis better, similar to the report by Zoltie et al. [13], this study may not have given conclusive evidence about this matter. A onetailed, well-structured, and randomized study may be better to draw unequivocal conclusions. Also, the change in the clinical features and clinical diagnosis led to significant changes in the decisions made regarding operative treatment and incision types in the tramadol group compared to the placebo group. Most of the changes were favorable. Again, it may be tempting to assume that the effect of tramadol translates to better decisions making, resulting in a reduction in inappropriate operations and improvement in the selection of appropriate incision types. Unfortunately, the later assumption may be flawed because of the small number of patients used in that analysis and probably because of the design of this study. However, it is noteworthy that findings are not uniform regarding the effect of preoperative analgesia on the rate of inappropriate operations $[7,11,25,27]$.

The pattern of side effects was similar in the two groups; the side effects were non-severe and not unexpected for the tramadol group. There were no life-threatening events, and the pattern of side effects was similar to that reported by McHale et al. [28] on the use of narcotic analgesics. Although opiates can cause severe adverse effects, this is rare when they are administered in the recommended dose $[9,18,23]$. This statement is re-affirmed by the pattern of adverse effects in this study.

\section{Conclusion}

This study shows that preoperative use of analgesia in patients with acute abdomen will not mask clinical signs while alleviating the pain experienced by patients. Rather, it may improve the gathering of clinical signs and may potentially help in decision-making.

\section{Abbreviations}

ED: Emergency department; TRA: Tramadol; WFI: Water for injection.

\section{Competing interests}

There are no competing interests. The study was not supported or funded by any organization, institution or individual. The materials used, including the active agent, were funded solely by the authors.

\section{Authors' contributions}

AS was involved in the conception of the study, design of the study, literature search, collection of data, statistical analysis, drafting of the manuscript, and review of the manuscript. OA was involved in the conception of the topic, design of the study, data analysis, and drafting of the manuscript. AM was involved in the conception of the study, literature search, analysis of the data, drafting of the manuscript, and review. AA was involved in the design of the study, data analysis, and the drafting and review of the manuscript. OK was involved in the design of the study, data collection, statistical analysis, and drafting of the manuscript. OB was involved in data collection, drafting and review of the manuscript. All authors were involved in the review of the available literature and review of the manuscript, and all have agreed that the manuscript be sent to the International Journal of Emergency Medicine for possible publishing.

\section{Acknowledgement}

We acknowledge Dr. G.A. Rahman of the Department of Surgery, University of Ilorin Teaching Hospital, for helping to review the article and Dr. G.

Oyeyemi of the Statistics Department of the University of Ilorin for reviewing and offering suggestions on the statistical analysis.

\section{Author details}

${ }^{1}$ Department of Surgery, LAUTECH Teaching Hospital, Osogbo, Nigeria. ${ }^{2}$ Department of Surgery, Obafemi Awolowo University Teaching Hospital Complex, Ile- Ife, Nigeria. ${ }^{3}$ Department of Obstetrics and Gyneacology, Obafemi Awolowo University Teaching Hospital Complex, lle- Ife, Nigeria.

Received: 12 April 2012 Accepted: 10 December 2012

Published: 23 January 2013

\section{References}

1. Gerard M, John H: The Acute Abdomen. In Current surgical diagnosis and treatment. 11th edition. Edited by Lawrence W, Gerard M. New York, USA: McGraw-Hill Medical Publishing Division; 2003:503-516.

2. Scott R, Jeffrey A: Acute Abdomen. In Sabiston textbook of surgery: the biological basis of modern surgical practice. 17th edition. Edited by Townsend C, Beauchamp R, Evers M, Matton K. Philadelphia USA: Saunders; 2003:1219-1239.

3. Naaeder S: The Acute Abdomen. In Principles and practice of surgery, including pathology in the tropics. 3rd edition. Edited by Badoe EA, Archampong EQ, da Rocha-Afodu JT. Accra Ghana: Ghana Publishing Corporation; 2000:503-508.

4. Dang C, Aguilera P, Dang A, Salem L: Acute abdominal pain. Four classifications can guide assessment and management. Geriatrics 2002, 57(3):30-42

5. Murtagh J: Acute abdominal pain: a diagnostic approach. Aust Fam Physician 1994, 23(3):358-374. 
6. Scheye: Surgical management of acute abdominal pain in children. $J$ Chir (Paris) 1999, 136(5):252-256.

7. Fisher JE, Nussbaum MS, Chance WT, Luchette F: Manifestation of Gastrointestinal Diseases. In Principles of surgery. 7th edition. Edited by Schwartz M. Boston, USA: Enigma Electronic Publication; 1999:108-172.

8. Andrew JD, Kalyanakrishnan R: Analgesic in the initial management of acute abdominal pain. Internet J Emerg Med 2005, 2. http://www.ispub.com/journal/ the-internet-journal-of-emergency-medicine/volume-2-number-2/analgesicsin-the-initial-management-of-acute-abdominal-pain.html.

9. Brewster GS, Herbert ME, Hoffman JR: Medical myth: analgesic should not be given to patients with an acute abdomen because it obscured the diagnosis. West J Med 2000, 172(3):209-210.

10. Ayoade AB, Tade AO, Salami AB, Oladapo O: Administration of analgesics in patients with acute abdominal pain: a survey of the practice of doctors in a developing country. Int J Emerg Med 2009, 2:211-215.

11. Attard AR, Corlett MJ, Kidner NJ, Leslie AP, Fraser IA: Safety of early pain relief for acute abdominal pain. BMJ 1992, 305:554-556.

12. Wolfe JM, Lein DY, Lenkoski K, Smithline HA: Analgesic administration to patients with an acute abdomen: a survey of emergency medicine physicians. Am J Emerg Med 2000, 18(3):250-253.

13. Zoltie N, Cust MP: Analgesia in the acute abdomen. Ann R Coll Surg Engl 1986, 68(4):209-210.

14. Rupp T, Delaney KA: Inadequate analgesia in emergency medicine. Ann Emerg Med 2004, 43(4):494-503.

15. LoVecchio F, Osler N, Kai S, Nelson LS, Flashber S, Finger R: The use of analgesics in patients with acute abdominal pain. J Emerg Med 1997, 15(6):775-779.

16. McHale PM, LoVecchio M: Narcotic analgesia in acute abdomen-a review of a prospective trial. Eur J Emerg Med 2001, 8(2):131-136.

17. Quinn J: Debunking the myths about analgesia. CMAJ 1994, 151(7): 914-915.

18. Monyano J, Figueras A: A review of opioid prescription in a teaching hospital in Colombia. J Pain Res 2012, 5:237-242.

19. Ranji SR, Goldman LE, Simel DL, Shojania KG: Do opiates affect the clinical evaluation of patients with acute abdominal pain. JAMA 2006, 14:1764-1774.

20. Aisuodionoe-Shadrach OI, Olapade-Olaopa EO, Soyannwo OA: Preoperative analgesia in emergency surgical care in Ibadan. Trop Doct 2006, 36(1):35-36.

21. Olawuyi JF: Biostatistics: A foundation course in health science. 1st edition. Ibadan Nigeria: Tunji Alabi printing Company; 1996:110-117.

22. Tait IS, lonescu MV, Cuschieri A: Do patients with acute abdominal pain wait unduly long for analgesia? J R Coll Surg Edinb 1999, 44(3):181-184

23. Mills AM, Edwards JM, Shofer SF, Holena DW, Abbuhl SB: Analgesia for older adults with abdominal and back pain in emergency department. West J Emerg Med 2011, 12:43-50.

24. Ohene-Yeboah M, Adippah E, Gyasi-Sarpong K: Acute intestinal obstruction in adults in Kumasi, Ghana. Ghana Med J 2006, 40(2):50-54.

25. Vermeulen B, Morabia A, Unger PF: Acute appendicitis: influence of early pain relief on the accuracy of clinical and US findings in the decision to operate-a randomized trial. Radiology 1999, 210(3):639-643.

26. Roger $\sqcup$ : The medical literature: A reader's guide. In Emergency medicine concepts and clinical practice. 4th edition. Edited by Rosen P, Barkin R, Danzl A, Mosby DF. Missouri USA: Time Mirror Company; 1998:276-297.

27. Manterola C, Pineda V, Vial W, Astudillo P: Use of opioid analgesics in diagnosis and decision-making in patients with acute nontraumatic abdominal pain. A systematic review of the literature. Cir Esp 2007, 81:91-95.

28. McHale PM, LoVecchio F: Narcotic analgesia in the acute abdomen-a review of prospective trials. Eur J Emerg Med 2001, 8(2):131-136.

doi:10.1186/1865-1380-6-3

Cite this article as: Agodirin et al:: Preoperative pain treatment in acute abdomen in Osogbo, Nigeria: a randomized double-blind placebocontrolled study. International Journal of Emergency Medicine 2013 6:3.

\section{Submit your manuscript to a SpringerOpen ${ }^{\circ}$ journal and benefit from:}

- Convenient online submission

- Rigorous peer review

- Immediate publication on acceptance

- Open access: articles freely available online

- High visibility within the field

- Retaining the copyright to your article

Submit your next manuscript at $>$ springeropen.com 